\title{
Patrimônio Edificado da USP e sua Preservação
}

Silvia Ferreira Santos Wolff*

Uma das questões centrais que envolvem a preservação do patrimônio edificado da Universidade de São Paulo, e que em certa medida o diferencia da ação preservacionista tradicionalmente feita em São Paulo, é a de que a grande maioria de seus prédios encontra-se em uso, aliás em pleno uso, em atividades ligadas ao ensino e à produção científica, com todo o dinamismo de transformações que essas áreas tem tido nesses últimos tempos.

$\mathrm{Na}$ verdade a questão da preservação do patrimônio cultural de um modo geral deve se dar em um plano em que os prédios a serem mantidos, referenciais simbólicos para a memória coletiva, abriguem atividades contemporâneas que os "(re)vitalizem" no caso de serem desativados. E de fato sempre que se preserva, ou principalmente se realiza obras de manutenção ou especialmente restauração se busca destinar as edificações para usos que tornem os investimentos justificados.

Mas não é esse o panorama que caracteriza de modo amplo o patrimônio edificado da USP, seja ele preservado através da chancela do tombamento ou não. E não é sobre esse tipo de ocorrência, de algum modo já percorrido nas intervenções em patrimônio tombado, que se dará ênfase nesse artigo.

O que caracteriza em grande medida o patrimônio edificado da Universidade é a demanda extremada por espaços disponíveis para a ampliação de departamentos, para a criação de novas seções, para instalação de novos equipamentos, para funcionamento e abrigo de insuspeitadas funções que se renovam a cada dia.

Neste sentido as iniciativas para manutenção do patrimônio edificado da USP devem fazer parte de uma visão mais contemporânea de preservação. Nas ações mais recentes tanto para elaborar critérios de seleção e atribuição de valor de bens culturais como suportes da memória coletiva, quanto para a elaboração de propostas de como sua preservação deve ser feita, leva-se em consideração que os espaços e as cidades transformam-se sempre e esse processo não pode, nem deve, ser bloqueado. Não sendo impedidas as mudanças como elas deverão ser feitas?

Tratou-se do patrimônio da USP de modo genérico, mas há situações e características diferenciadas. Há prédios antigos que tem seu valor reconhecido para além de seu significado vinculado à história de produção de conhecimento da 
própria instituição. Edifícios reconhecidos pela história da arquitetura e pela própria história urbana paulista. São exemplos notáveis desse tipo de acervo o Museu Paulista e dois edifícios residenciais localizados na cidade de São Paulo - Casa de Dona Yayá e Vila Penteado.

Não por acaso se inicia esse artigo mencionando esses prédios. Os dois, residenciais, são representativos dos problemas tradicionalmente mais corriqueiros na tradição da prática de preservação em São Paulo. São edificações notáveis, antigas, representativas de técnicas e modos de vida do passado e que hoje integram o acervo da Universidade. A conservação dessas construções exige cuidados especiais que pertencem ao campo da restauração. Ao mesmo tempo o uso dos espaços condicionam-se a alguns limites impostos por características da arquitetura que devem ser mantidas.

A própria definição de melhor utilização desses espaços originalmente concebidos para funções já extintas - do padrão de residências burguesas do século XIX - nem sempre são fáceis. E, como já se referiu, é do campo da preservação em geral a necessidade de utilizar bem espaços restaurados. Mesmo porque espaços vazios ou sub-utilizados deterioram-se rapidamente.

Nos exemplos citados do patrimônio da USP a destinação veio estabelecida desde a origem no caso da Vila Penteado, já que fez parte das condições impostas pelos doadores, que as instalações se mantivessem sempre como escola ligada às artes. ${ }^{1}$ A valorização crescente do prédio como monumento arquitetônico se deu progressivamente através de seu vínculo com a Faculdade de Arquitetura e Urbanismo, que nasceu nessa casa.

Já o exemplo de destinação da famosa Casa de Dona Yayá, atualmente ocupada com muito sucesso, ainda não permite esquecer as décadas em que permaneceu fechada, entre outras razões, em busca de função adequada para seus espaços. Como ela a antiga Tulha de Café e a Casa do Administrador da Fazenda Monte Alegre em Ribeirão Preto (campus USP). Edifícios hoje recuperados, mas por anos invadidos pelo mato e dilapidados por atos de vandalismo. Como esses deve haver outros casos que agora não ocorre citar.

Por outro lado, há no patrimônio edificado da Universidade prédios que permanecem com exatamente o mesmo uso para o qual foram projetados como os Museus de Zoologia e em certa medida o Paulista, ambos localizados no bairro do Ipiranga. Especialmente no caso do Museu Paulista, reconhecido com patrimônio 
nacional, a manutenção de suas características arquitetônicas, ornamentais e construtivas, já inscreve as intervenções necessárias no campo dos especialistas, no campo das restaurações. No caso desses museus, contudo, há poucas demandas que impliquem em alterações consideráveis de funções do espaço, sendo as exigências basicamente da delicada conservação e adequações de infra estrutura para inserções tecnológicas e adaptações para melhor conforto dos visitantes, a fonte de maiores reflexões e cuidados. Como instalar nova rede elétrica e circulação vertical mecanizada? Temas, aliás, comuns a todas as construções antigas que visam modernizar-se para usos atuais, mas que se tornam mais delicados em monumentos nacionais como o famoso Museu do Ipiranga.

A modernização e reformulação da infra-estrutura em construções antigas fazem parte da essência da prática da preservação do patrimônio edificado em geral. Haverá alguma especificidade no caso da USP?

Parece que sim. Há, em primeiro lugar, a dimensão do conjunto sob responsabilidade exclusiva da Universidade, e ainda, a intensidade de sua utilização, a constante necessidade de renovação e a dificuldade de racionalização nas atribuições dos espaços. E essa parece ser a dimensão mais importante. Independente de reconhecimento de valor cultural há territórios de atribuições consolidadas e pouco permeáveis à necessidade de mudanças e de adensamento, fatores aliados a uma constante busca por intensificação de uso de espaços que não se pode desperdiçar.

Quase se pode considerar um contra-senso a perda no passado pela Universidade de conjuntos de grandes dimensões e extremo valor cultural. Tal perda, entre outros aspectos, se deu pelo não reconhecimento desse valor. São exemplos de edifícios ligados às origens do ensino acadêmico em São Paulo, antes mesmo da fundação da USP, como o da Faculdade de Farmácia e Odontologia e da Escola Politécnica, ambos no Bom Retiro, hoje pertencentes ao Estado e ao Município e não mais à USP.

Caberia um aprofundamento que não faz parte do tema deste texto investigar as motivações do abandono dos prédios centrais e urbanos, preteridos em função das novas instalações na Cidade Universitária. Seria talvez precipitado atribuir todas essas mudanças apenas a questões de ordem política como a da traumática história da Faculdade de Filosofia, transferida da rua Maria Antonia para barracões no Butantã no período da ditadura militar. Mas a manutenção da 
Faculdade de Direito no largo São Francisco e do conjunto das escolas médicas em Pinheiros, o apego até hoje de suas comunidades ao lugar em que nasceram pedem cuidado nas interpretações.

A retomada da Maria Antonia pela USP com a instalação de uma dinâmica unidade ligada a atividades culturais pode ser lembrada como a de um prédio que não exigiu muitos cuidados para ter suas instalações recuperadas e que rapidamente foi preenchido com muita vitalidade.

A busca por espaços disponíveis para a ampliação de departamentos, para a criação de novas seções e para instalação de novos equipamentos são elementos que muito além das questões específicas da preservação do patrimônio cultural dizem respeito a planejamento, a elaboração de planos diretores, a revisão das destinações existentes. Tarefa difícil e necessária que já vem sendo aos poucos realizada em algumas unidades. Precisam crescer dentro de suas instalações prédios que podem chegar a ter mais de cinqüenta anos e que permanecem sendo ocupados por salas de aula, anfiteatros, laboratórios. Prédios como, por exemplo, os das referidas Faculdade de Medicina e Faculdade de Direito de São Paulo.

Ligeiramente diferente é o caso dos campi como o da Escola Agrícola de Piracicaba, o da antiga Faculdade de Medicina de Ribeirão Preto, o da Escola Agrícola de Pirassununga. Lá, nos prédios centrais, há o mesmo tipo de questão que incide sobre a Faculdade de Medicina ou a Faculdade de Direito - é necessário que sejam conservados, mantidos em funcionamento e adequados às novas necessidades: salas para projeções audiovisuais, informática, com a respectiva reestruturação de redes elétricas, sem esquecer as adequações às novas leis que visam o acesso a todos, inclusive portadores de necessidades especiais.

Mas há também nesses campi de grandes dimensões vários prédios cuja finalidade original já se perdeu. A Escola Agrícola de Piracicaba, criada no início do século $X X$, à semelhança de uma fazenda, previa habitações para diretores, professores e funcionários, subdivididos no espaço de forma hierarquizada. Mesmo esquema que foi reproduzido nos anos 1940 em Ribeirão Preto e Pirassununga. O padrão, que se revelou extremamente eficaz como um atrativo para a contratação de professores para longe dos grandes centros, ou mesmo viabilizou o funcionamento das fazenda-escolas não se justifica atualmente. Com as residências desativadas tornam-se áreas extremamente bem-vindas na disputa acirrada por espaço no 
processo de expansão dos departamentos. O que dizer de estábulos e pocilgas já não mais utilizados como tal?

O risco é que no afã das ocupações, nem sempre os destinos são os mais adequados do ponto de vista da localização mais racional, do uso mais adequado. Mais uma vez aspectos ligados ao gerenciamento e menos a questões específicas da preservação do patrimônio.

Estabelecido o panorama e caracterização do patrimônio edificado da USP e suas interfaces com o campo da preservação resta refletir sobre as perspectivas para a continuidade da manutenção desse acervo.

Por que e para que preservar? Que papel cabe aos órgãos oficiais? Qual é a atribuição da Universidade? Pouco necessário dizer sobre a pertinência da manutenção de marcos simbólicos de uma história de mais de cem anos de investimentos e de produção de ciência no Estado de São Paulo. São edifícios que abrigam vestígios e acervos científicos que precedem a criação da própria Universidade em 1934.

De qualquer modo, cabe inegavelmente aos órgãos de preservação o papel de identificar, reconhecer, relacionar, trazer a luz e valorizar esse patrimônio. Por mais que a história tenha compartimentado, por exemplo, as diversas instituições que se desenvolvem em torno da Faculdade de Medicina de Pinheiros, cabe aos órgãos de preservação explicar porque aquela área teve seu destino ligado à Saúde Pública, com origens que remontam ao século XIX e ao desenvolvimento urbano de São Paulo e que foram impulsionadas por investimentos norte-americanos, mais tarde nos anos 1920, antes mesmo da constituição da Universidade.

As instituições oficiais ligadas ao patrimônio deverão divulgar, ainda, por exemplo, como a utopia de um visionário transformou, a Escola Agrícola Luis de Queirós em Piracicaba em marco e produto de conhecimento sobre culturas agrícolas desde o início do século XX, com forte crescimento nos anos 1940. Explicitar e divulgar o sentido social da origem dessas instituições é papel dos institutos de preservação.

E caberá ainda, primordialmente, aos órgãos de preservação zelar para que esse reconhecimento e divulgação do papel que esse patrimônio edificado tem e teve na história cultural do país, não crie obstáculos para a continuidade do funcionamento dessas instituições. Para isso devem ser fornecidos parâmetros para 
as adaptações necessárias. Desse modo salas de aula deverão continuar funcionando, assim como laboratórios, campos de cultivo e hospitais.

Nesse sentido já se iniciaram ações e encontros entre representantes do órgão estadual de preservação Condephaat e membros e representantes de diversas unidades e coordenadorias da USP - responsáveis por acervos tombados, pelo patrimônio cultural, CPC, e pelas construções e manutenções dos edifícios do patrimônio da Universidade, COESF.

E à Universidade que papel se atribui? O de efetiva e inequívoca guardiã de todo esse patrimônio do qual é em grande parte a produtora. Para tal deverá realizar planos para que as transformações processem-se organizadamente.

Estabelecidas atribuições específicas para a Universidade e para os órgãos oficiais no trato desse patrimônio cultural e esferas de colaboração mútua a questão central retorna: como preservar esses prédios em pleno funcionamento, atendendo às exigentes demandas das transformações das práticas de ensino e, principalmente, às exigências de modernização das funções que abrigam? Quais parâmetros e diretrizes deverão ser seguidos? Como fazer essas intervenções sem ferir a integridade dos edifícios, sem descaracterizá-los? Haverá regra que guie cada mudança?

Sempre se poderá recorrer às normas e cartas internacionais. ${ }^{2}$ Mas, são documentos e referências próprios ao campo de especialistas. De fato, como na prática da preservação em geral não há uma resposta padrão. Cada caso deverá ser examinado. Haverá exemplares como o do Museu Paulista ou da Vila Penteado em que cada projeto deverá ter elaboração muito ponderada e cuidadosa de modo a não desfigurar a identidade desses monumentos ligados à história da arquitetura do século XIX. Será assegurada assim a manutenção de aspectos de integridade e excepcionalidade que caracterizam esses edifícios como marcos reconhecidos e valorizados.

Haverá outros, contudo, em que ampliações e até supressões de partes serão necessárias e possíveis. Nesse caso a única lei a ser transmitida será a de que deve ser observado o mais alto grau de harmonia entre a arquitetura existente e a que a ela se agrega. Nesse caso os critérios dirão respeito a opções de articulação e equilíbrio, de massas e volumes e de sintonia de cores, materiais e texturas. Escolhas do campo da arquitetura. 


\section{Notas}

${ }^{1}$ ver PIRES, Walter e WOLFF, Silvia Ferreira Santos. Vila Penteado: Fau Maranhão. CPC-USP. Relatório de pesquisa (mimeo). São Paulo, 1989.

${ }^{2}$ IPHAN, Cartas Patrimoniais, $2^{\mathrm{a} e d .}$ ver. aum. Rio de Janeiro: Iphan, 2000.

\section{Referências Bibliográficas}

A CASA de Dona Yayá. 2aed. São Paulo: Edusp/ Imprensa Oficial, 2001. (Cadernos CPC, 3)

BENS IMÓVEIS TOMBADOS OU EM PROCESSO DE TOMBAMENTO DA USP. São Paulo: Edusp/ Imprensa Oficial, 1999. (Cadernos CPC, 2)

CIDADES UNIVERSITÁRIAS: PATRIMÔNIO URBANÍSTICO E ARQUITETÔNICO DA USP. São Paulo: Edusp/ Imprensa Oficial, 2005. (Cadernos CPC, 7)

KAMIDE, Edna H. e PEREIRA, Tereza Cristina E. (coord.). Bens tombados 1968-1998. São Paulo: Imprensa Oficial, 1998.

* Arquiteta. Doutora pela FAUUSP. Arquiteta do Condephaat e Professora de História da Arquitetura e Urbanismo da FAAP. 